\title{
POLÍTICAS PÚBLICAS EM EDUCAÇÃO: A ESCOLA DE EDUCAÇÃO INFANTIL DA UFRJ FRENTE À RESOLUÇÃO No 1 DO CNE/MEC ${ }^{1}$
}

\author{
POLÍTICAS PÚBLICAS EN EDUCACIÓN: LA ESCUELA DE EDUCACIÓN \\ INFANTIL DE LA UFRJ FRENTE A LA RESOLUCIÓN N 1 DEL CNE / MEC
}

\author{
PUBLIC POLICIES IN EDUCATION: THE SCHOOL OF CHILDREN \\ EDUCATION OF UFRJ WITH THE RESOLUTION N 1 OF THE CNE / MEC
}

\author{
José Jairo VIEIRA ${ }^{2}$ \\ Isabela Pereira LOPES ${ }^{3}$ \\ Andréa Lopes da Costa VIEIRA ${ }^{4}$
}

RESUMO: Este artigo procurou compreender os impactos das atuais políticas públicas direcionadas às unidades de educação infantil federais, principalmente no momento atual, quando legislações e políticas públicas estão inquietando esses espaços e atribuindo-lhes novos significados e demandas. Neste estudo, foi utilizada a Escola de Educação Infantil da UFRJ diante de Resolução do Conselho Nacional de Educação,

\footnotetext{
1 Uma versão preliminar deste trabalho foi apresentada no III Seminário Internacional Inclusão em Educação: Universidade e Participação, Lapeade/PPGE/UFRJ, Rio de Janeiro, 2013.

${ }^{2}$ PPGE - UFRJ. Email: diversidade.desigualdade.educa@gmail.com

${ }^{3}$ Doutoranda em Educação pela Universidade do Estado do Rio de Janeiro. Mestra em Educação pela Universidade Federal do Rio de Janeiro (2014). Possui graduação em Pedagogia pela Universidade Federal Fluminense (2006) e Especialização em Políticas Públicas pela Universidade Federal do Rio de Janeiro (2012). Técnica em assuntos educacionais da Universidade Federal do Rio de Janeiro, atuando como Coordenadora na Escola de Educação Infantil da UFRJ. Foi Integrante do Grupo Gestor da Escola de Educação Infantil da UFRJ. Atua como Professora II na SEMED Nova Iguaçu, atuando na Subsecretaria Pedagógica de Coordenação da Educação de Jovens e Adultos. Tem experiência na área de Educação, atuando principalmente nos seguintes temas: educação infantil, infância, políticas públicas e formação docente. Email: diversidade.desigualdade.educa@gmail.com

${ }^{4}$ Possui graduação em Ciências Sociais pela Universidade Federal do Rio de Janeiro, mestrado em Ciências Sociais: Sociologia pelo Instituto Universitário de Pesquisa do Rio de Janeiro - IUPERJ e doutorado em Ciências Sociais: Sociologia pelo Instituto de Universitário de Pesquisa do Rio de Janeiro IUPERJ. É Professora Associada I no Departamento de Ciências Sociais da Universidade Federal do Estado do Rio de Janeiro (UNIRIO), onde também integra o quadro permanente do Programa de PósGraduação em Memória Social (PPGMS). Tem experiência na área de Sociologia, com ênfase em Sociologia Política, atuando principalmente nos seguintes temas: ações afirmativas, acesso e permanência no ensino superior, políticas sociais, desigualdades sociais, relações raciais e relações de gênero. Desenvolve ainda trabalhos na área de memória social, em especial, na inter-relação entre memória, identidade e espaço. Coordena o GT de Relações Raciais e Étnicas: Desigualdades e Políticas Públicas na Sociedade Brasileira de Sociologia. Email: diversidade.desigualdade.educa@gmail.com
} 
que entre outros pontos democratiza o acesso às unidades de educação infantil universitárias, espaços que em sua maioria, durante décadas, foram entendidos como benefício de alguns poucos servidores e estudantes. Os desafios que a Escola de Educação Infantil da UFRJ tem enfrentando para constituir sua nova identidade, no início da implantação de uma política pública, são problematizados. Dialogo com alguns autores que procurar explicar o histórico da educação infantil tão relacionado ao assistencialismo (Costa, Nunes, Ghon) e que pensa especificamente isso aplicado às creches universitárias (Raupp). Observando o histórico de cada creche universitária, é possível perceber que cada uma buscou estratégias para a sua legitimação e para se destacar no campo acadêmico. Se ainda hoje é possível notar que muitas dessas creches ainda mantêm vínculos iniciais, firmados há décadas, fica fácil entender o desconforto gerado pela Resolução e os desafios que serão enfrentados por esses espaços.

PALAVRAS-CHAVE: Politica Públicas. Universidade. Creche universitária.

RESUMEN: Este artículo buscó comprender los impactos de las actuales políticas públicas dirigidas a las unidades de educación infantil federales, principalmente en el momento actual, cuando legislaciones y políticas públicas están inquietando esos espacios y atribuyéndoles nuevos significados y demandas. En este estudio, se utilizó la Escuela de Educación Infantil de la UFRJ ante la Resolución del Consejo Nacional de Educación, que entre otros puntos democratiza el acceso a las unidades de educación infantil universitarias, espacios que en su mayoría, durante décadas, se entendieron como beneficio de algunos Pocos servidores y estudiantes. Los desafíos que la Escuela de Educación Infantil de la UFRJ ha enfrentado para constituir su nueva identidad, al inicio de la implantación de una política pública, son problematizados. Dialogo con algunos autores que tratar de explicar el histórico de la educación infantil tan relacionado al asistencialismo (Costa, Nunes, Ghon) y que piensa específicamente eso aplicado a las guarderías universitarias (Raupp). Observando el histórico de cada guardería universitaria, es posible percibir que cada una buscó estrategias para su legitimación y para destacarse en el campo académico. Si aún hoy es posible notar que muchas de esas guarderías todavía mantienen vínculos iniciales, firmados desde hace décadas, resulta fácil entender la incomodidad generada por la Resolución y los desafíos que serán enfrentados por esos espacios.

PALABRAS CLAVE: Política Pública. Universidad. Guardería universitaria.

ABSTRACT: This article sought to understand the impacts of current public policies directed at federal child education units, especially at the current moment, when legislations and public policies are disturbing these spaces and attributing them new meanings and demands. In this study, the School of Early Childhood Education of UFRJ was used in response to a Resolution of the National Education Council, which, among other points, democratizes access to university elementary education units, spaces that for the most part were understood for the benefit of some Few servers and students. The challenges that the School of Early Childhood Education of UFRJ has 
been facing in order to constitute its new identity, at the beginning of the implementation of a public policy, are problematized. Dialogue with some authors that seek to explain the history of early childhood education so closely related to welfare (Costa, Nunes, Ghon) and that specifically thinks this applied to university daycare (Raupp). Observing the history of each university day care center, it is possible to perceive that each sought strategies for its legitimation and to stand out in the academic field. If it is still possible today to note that many of these day care centers still have initial ties signed decades ago, it is easy to understand the discomfort generated by the Resolution and the challenges that will be faced by these spaces.

KEYWORDS: Public Policy. University;. University nursery school.

\section{Introdução}

A educação infantil ao longo das décadas vem tomando o seu devido lugar no palco das discussões acadêmicas e nas lutas dos movimentos sociais. Questionar estes espaços significa sinalizar suas identidades, marcadas ao longo do tempo por traços assistencialistas e higienistas que provocam marcas que perduram até hoje.

Este trabalho faz parte da dissertação de mestrado, em andamento, que procurar compreender os impactos das atuais políticas públicas direcionadas às unidades de educação infantil federais, principalmente no momento atual, quando legislações e políticas públicas estão inquietando esses espaços e atribuindo-lhes novos significados e demandas. Será utilizada neste estudo, a Escola de Educação Infantil da UFRJ diante da Resolução $\mathrm{N}^{\mathrm{o}} 1$, que entre outros pontos democratiza o acesso às unidades de educação infantil universitárias, espaços que em sua maioria, durante décadas, foram entendidos como benefício de alguns poucos servidores e estudantes.

\section{Reunindo as histórias: do assistencialismo à luta por democratização}

A instituição educacional formalizada para crianças pequenas foi surgir posteriormente à escola, que era destinada para crianças maiores. Na Europa, Friedrich Froebel vai fundar a primeira iniciativa propriamente dita de atenção à primeira infância, os chamados Kindergarden (jardins-de-infância) no final do século XIX. 
Fica claro nos estudos de Costa (1979), como era difícil cuidar das crianças brasileiras no século XIX, livrando-as das inúmeras doenças e da alta mortalidade que assolava, principalmente, os infantes.

As primeiras experiências em creches foram possíveis apoiadas por descobertas científicas, principalmente no campo da microbiologia, que tornou possível, por exemplo, uma amamentação artificial, que independia a mãe de trabalhar. No Brasil inicialmente chegaram as ideias, inspiradas por creches já consolidadas na França, desde o final do século XIX.

Pensar na história social das instituições para a primeira infância é tocar na questão higienista. A medicina social foi grande responsável pela política higiênica. Esta conseguiu transformar a instituição familiar numa dependente seguidora de suas normas, através de um discurso iluminista e pontual. Para Costa (1989, p. 12) a história mostra como essa pedagogia médica ultrapassou os limites da saúde individual. $\mathrm{O}$ autor levanta indícios da época que demonstram como essa higiene enquanto alterava o perfil sanitário da família, modificou também sua feição social.

O surgimento da creche se deu após o aparecimento da escola, que assumia um papel de complementar a educação familiar para as crianças maiores. A preocupação com uma educação complementar e especializada para crianças menores, somado ao trabalho materno fora do lar, após a Revolução Industrial, propiciou o surgimento de espaços destinados a cuidar desses filhos de mães trabalhadoras.

As creches surgiram numa tentativa de atender as demandas e mudanças econômicas, políticas e sociais, para suprir. Uma dessas mudanças foi a incorporação de mão-de-obra feminina ao trabalho assalariado. Essa inserção feminina proporcionou um novo papel atribuído à mulher e uma nova dinâmica na relação entre os sexos.

Segundo Vieira (1986) e Kishimoto (1988) essas iniciativas empresariais, que procuravam garantir a incorporação das mulheres, como mão-de-obra nessas fábricas, foram determinantes no surgimento das primeiras creches.

Assim, podemos perceber que o nascimento da creche no Brasil acontece a partir da demanda das mulheres, e da inserção delas no mercado de trabalho. Trabalho feminino e creche, desde o início do século XX, implicam-se mutuamente.

Havia uma crescente mobilização de luta das classes de trabalhadores. Portanto, inicialmente, a reivindicação por creches não estava em discussão no debate da classe trabalhadora. As iniciativas para a infância eram puramente assistencialistas e, pouco a pouco, foram ganhando novo lugar social. 
Segundo Ghon (1990), apenas nas décadas de 1970 e 1980 a creche passa a ser uma demanda popular, desencadeando a Constituição de 1988, quando a educação infantil passa a ser concebida como direito para as crianças de 0 a 6 anos.

Mas para Nunes (2000, p. 104) o contexto social dos anos de 1990 parece ainda carregar um complexo sistema de crenças e valores que ainda impedem o reconhecimento social da infância. A existência das creches ligadas às universidades e instituições federais, ainda como benefício de seus funcionários, é um sinal da conservação desta perspectiva assistencialista e que despotencializa a criança, principalmente quando o funcionamento destas instituições acontece prioritariamente para atender a demanda das famílias e não das crianças.

Foi no contexto de lutas sociais e trabalhistas, que as primeiras instituições de Educação Infantil ligadas a órgãos da Administração Pública Federal surgiram, como conquista dos servidores e não das crianças.

A Consolidação das Leis do Trabalho (CLT), regulamentada através do Decreto Lei $\mathrm{n}^{\circ} 5.452$, de $1^{\circ}$ de maio de 1943 já sinalizava a exigência de um espaço destinado às trabalhadoras, para que estas pudessem guardar os seus filhos nos períodos de amamentação, em locais de trabalho com pelo menos trinta mulheres. Depois outras iniciativas foram tomadas pelo Departamento Nacional de Segurança e Higiene do Trabalho (DNSHT), mas apenas no sentido da trabalhadora ter o direito garantido de amamentar durante a jornada de trabalho.

\section{A creche como benefício do servidor: as primeiras experiências}

No contexto de lutas e conquistas crescentes, surgiram as primeiras unidades destinadas à Educação Infantil, em universidades federais brasileiras. A pioneira neste sentido foi a Universidade Federal de São Paulo, em 1971, seguida da creche da Universidade Federal do Rio Grande do Sul. Estas creches consolidaram-se no contexto educacional, inspirando práticas para o surgimento de novas creches universitárias e para a educação brasileira.

No que diz respeito às creches universitárias, pode-se dizer que a década de 1980 representa um momento de expansão. Uma explicação para essa multiplicação de creches federais foi o Decreto $\mathrm{n}^{\circ}$ 93.408, de 10 de outubro de 1986, que apresentava a 
creche no local de trabalho como um direito para servidores federais, homens e mulheres.

É importante notar que se estabelece aí um retrocesso e uma contradição. Ao mesmo tempo em que o país vive a conquista do direito por parte das crianças da educação em creches e pré-escolas, garantido pela Constituição de 1988, outra medida legal garante o atendimento nestas instituições como benefício dos servidores federais. Até hoje, as creches universitárias vivem os desdobramentos desta situação política.

Neste contexto de creche como benefício, surgiu no Rio de Janeiro, a Creche Universitária Pintando a Infância, da Universidade Federal do Rio de Janeiro, que atualmente denomina-se Escola de Educação Infantil da UFRJ. Inspirada por uma cultura higienista e que relacionava Educação e Saúde como indissociáveis, esta creche foi instalada e lá permanece até os dias atuais nas instalações do Instituto de Puericultura e Pediatria Martagão Gesteira (IPPMG). Administrativamente, a creche deixou de ser setor do hospital em 1987, passando a ser estrutura da Divisão de Assistência Médica do Servidor. No início da década de 1990 passou a fazer parte da Superintendência Geral de Pessoal e Serviços Gerais (PR-4), onde permanece nos dias atuais

No que diz respeito à legislação, se a Constituição foi um grande passo para as creches, depois inúmeros documentos confirmaram e trataram de especificar as demandas da Educação Infantil. A Lei de Diretrizes e Bases da Educação Nacional (LDB), Lei nº 9.394, de 1996, por exemplo, estabelece o atendimento às crianças de $0 \mathrm{a}$ 6 anos, como primeira etapa da Educação Básica.

Para entender o processo de criação das creches federais, é essencial entender o impacto do Decreto $n^{\circ}$ 977, de 10 de Novembro de 1993, pois este vedou a criação de outras creches universitárias.

No contexto das conquistas legais e discursivas no campo da infância e da Educação Infantil, o MEC institui a Resolução $\mathrm{N}^{\mathrm{o}}$ 1, do Conselho Nacional de Educação, de 10 de Março de 2011, nele foram fixadas normas de funcionamento das unidades de Educação Infantil, universitárias e/ou federais. A Resolução vai estabelecer vários pontos, mas alguns que merecem destaque:

I - oferecer igualdade de condições para o acesso e a permanência de todas as crianças na faixa etária que se propõem a atender; 
II - realizar atendimento educacional gratuito a todos, vedada a cobrança de contribuição ou taxa de matrícula, custeio de material didático ou qualquer outra;

Essa resolução surgiu de uma consulta feita pela Associação das Unidades Universitárias Federais de Educação Infantil (ANUUFEI), que encaminhou consulta à Câmara de Educação Básica do Conselho Nacional de Educação buscando esclarecimento e orientação quanto à regulamentação de normas de funcionamento. A ANUUFEI é uma organização que procura favorecer a integração dessas unidades, representando-as, inclusive judicialmente.

Após a publicação da resolução em Diário Oficial, o que foi possível perceber foi um movimento de reuniões internas, seguido de um contato mais próximo com outras unidades dentro do Rio de Janeiro e culminando com o Encontro Anual da ANUUFEI de 2011.

A Escola de Educação Infantil da UFRJ já tem tomado cuidado ao elaborar documentos de ação em longo prazo. Se antes o Edital para acesso a escola era um sorteio aberto exclusivamente para filhos de servidores (técnicos e docentes) sem distinção entre estes, para o ano de 2012, esse sorteio ampliou a tentativa para filhos de estudantes da graduação e de pós-graduação na modalidade stricto sensu.

Com base no Artigo $1^{\circ}$, inciso I, da Resolução $N^{\circ} 1$, do MEC, de 10 de Março de 2011, o Edital referente às vagas para o ano de 2013, garantirá o acesso universalizado à Escola de Educação Infantil da UFRJ, não havendo reserva de vagas. 7.2 A partir deste Edital fica vedada a matrícula dos irmãos de qualquer criança que venha frequentar a Escola de Educação Infantil no ano de 2012, tendo em vista a universalização do acesso em 2013.

Esse documento já sinaliza que a EEI-UFRJ pretende manter-se vinculado ao Ministério da Educação e simultaneamente, conquistar sua identidade enquanto unidade de educação infantil federal, esmiuçada na Resolução $\mathrm{N}^{\circ} 1$.

Atualmente a Escola de Educação Infantil tem se reunido constantemente com seus profissionais, no intuito de revisar sua Proposta Pedagógica e Resolução, contando inclusive com a parceria da Faculdade de Educação da UFRJ e com docentes de outras instituições que tem contribuído para ampliar o debate a respeito da escola que temos e daquela que queremos. 
A institucionalização também continua seus trabalhos, com os outros interlocutores, através do GT instituído pós-Resolução, visando à inclusão do debate acerca da EEI como órgão suplementar do Centro de Filosofia e Ciências Humanas.

Portanto é possível notar que a Resolução $N^{\circ}$ 1, na Universidade Federal do Rio de Janeiro, já conseguiu conflagrar uma movimentação institucional em prol de fazer com que a Escola de Educação Infantil da UFRJ permaneça como unidade de educação infantil cumprindo o tripé universitário de ensino, pesquisa e extensão e ampliando o que já era realizado antes da inclusão de políticas públicas democratizantes no âmbito universitário. Se antes os atendidos eram crianças que faziam parte de um mínimo grupo beneficiário, daqui para frente, o que se pretende é que todas as famílias tenham oportunidade de pleitear acesso para seus filhos, neste espaço público e com investimento federal. É por isso que a maioria tem lutado.

\section{Considerações Finais}

Abordar a questão das unidades de educação infantil federais é ainda hoje mergulhar em uma temática pouco explorada. Raupp (2004, p. 5) já sinalizava as "dificuldades para encontrar conhecimento acumulado sobre creche universitária no âmbito das Ciências Sociais e, pela escassez de referências." Hoje essa procura ainda é dificultada por poucos estudos debruçados sobre as políticas desses espaços de educação infantil peculiares.

Observando o histórico de cada creche universitária, é possível perceber que cada uma buscou estratégias para a sua legitimação e para se destacar no campo acadêmico. Tal constatação fica clara quando percebemos as pouquíssimas unidades de educação infantis nas universidades brasileiras que estão vinculadas com centros de educação na universidade. Vários destes espaços estão submetidos a órgãos que não são "da Educação" (pró-reitorias, hospital, assistência social e até Departamento de Economia Doméstica). A UFRJ está incluída nessa alarmante estatística, já que sua Escola de Educação Infantil (EEI-UFRJ) está vinculada a PR-4, em outras palavras, Pró-reitoria de Pessoal, o que ainda hoje, 30 anos após a inauguração desse espaço, reforça sua função assistencialista. Somado a isso, o fato desta ter suas instalações no interior do IPPMG, que é o Instituto de Puericultura e Pediatria Martagão Gesteira. 
Se ainda hoje é possível notar que muitas dessas creches ainda mantêm vínculos iniciais, firmados há décadas, fica fácil entender o desconforto gerado pela Resolução e os desafios que esta apresenta para quem luta por esses espaços.

A Escola de Educação Infantil foi configurando a sua identidade com o passar dos tempos, demonstrando sua característica multifacetada, diante dos desafios que o cotidiano apresenta. A Resolução $N^{\circ}$ 1, com suas normas, apresentou-se como mais um desafio que a EEI-UFRJ e as creches federais brasileiras em geral, precisam encarar para transformar esse espaço em algo democrático e que alie o tripé universitário de ensino, pesquisa e extensão.

Deste modo, a Resolução $\mathrm{N}^{\mathrm{o}} 1$ acabou apresentando um caminho para estas creches, já que os passos para a aplicação estão sendo debatidos interna e externamente. Estas discussões geraram um movimento entre as creches federais de reconhecimento e fortalecimento entre as equipes destes espaços. Após a resolução foi possível notar encontros, diálogos, visitas guiadas às creches, além de fóruns com esta temática nas mesas de discussão.

Mas este trabalho demonstra inicialmente apenas o movimento de uma unidade, nas dezenas que temos espalhadas pelo Brasil. Portanto novos estudos serão necessários para cobrar e revelar se a Resolução está se fazendo cumprir nas unidades de educação infantil federais.

Após a Resolução No 1 a Escola de Educação Infantil pretende dar visibilidade há décadas de esquecimento, provisoriedade e poucas de suas muitas reivindicações atendidas. Hoje é possível vislumbrar a possibilidade de ver a Educação Infantil ter o seu merecido lugar no bojo da universidade.

\section{Referências}

BRASIL, Constituição da República federativa do Brasil. Brasília: Senado, 1988. Consolidação das Leis do Trabalho. Rio de Janeiro, 1943. Decreto $\mathrm{N}^{\circ}$ 93.408, de 10 de Outubro de 1986. 
Decreto $\mathbf{N}^{\mathbf{0}}$ 977, de 10 de Setembro de 1993.

DF.

LDB. Lei 9394/96 - Lei de Diretrizes e Bases da Educação Nacional. Brasília, Ministério da Educação. Conselho Nacional de Educação. Câmara de Educação Básica. Resolução No 1, de 10 de Março de 2011. Brasília, DF.

COSTA, Jurandir Freire. Ordem médica e norma familiar. Rio de Janeiro: Edições Graal, 1989.

EDITAL DE ADMISSÃO 2012 - ESCOLA DE EDUCAÇÃO INFANTIL (EEIUFRJ). Edital de 07 de Novembro de 2011. Rio de Janeiro. Disponível em: <www.pr4.ufrj.br/documentos/EDITAL_EEI_20112012_2.doc>. Acesso em: 27 mai 2012

GOHN, M. G. Educação Infantil: aspectos da legislação. Campinas: Departamento de Criança ao Projeto Jorge Haje, 1990 (mimeo).

KISHIMOTO, T. M. A pré-escola em São Paulo (1877-1940). São mPaulo: Loyola, 1988.

NUNES, D. G. Da roda à creche - proteção e reconhecimento social da infância de o a 6 anos. UFRJ, Tese de Doutorado em Educação, Rio de Janeiro, 2000.

RAUPP, M. D. Creches nas universidades federais: questões, dilemas e perspectivas. In: Educação \& Sociedade, Campinas, vol. 25, n. 86, p. 197-217, abril, 2004.

RAUPP, M. D. A educação infantil nas universidades federais: questões, dilemas e perspectivas. 2001. Dissertação (Mestrado em Educação) - UFSC, Santa Catarina.

VIEIRA, Lívia M. F. Creches no Brasil: do mal necessário a lugar de compensar carências: rumo à construção de um projeto educacional. Belo Horizonte: Faculdade de Educação da UFMG, 1986. Dissertação (mestrado). 


\section{Como referenciar este artigo}

VIEIRA, José Jairo et al. Políticas públicas em educação: a escola de educação infantil da UFRJ frente à resolução $n^{\circ} 1$ do CNE/MEC. Revista on line de Política e Gestão Educacional, Araraquara/SP, v.20, n.02, p. 223-236, 2016. Disponível em: <http://dx.doi.org/10.22633/rpge.v20.n2.9477>. ISSN: 1519-9029.

Submetido em: maio/2016

Aprovado em: novembro/2016 
RPGE- Revista on line de Política e Gestão Educacional, v.20, n2, p. 223-236, 2016 DOI: http://dx.doi.org/10.22633/rpge.v20.n2.9477 
RPGE- Revista on line de Política e Gestão Educacional, v.20, n2, p. 223-236, 2016 DOI: http://dx.doi.org/10.22633/rpge.v20.n2.9477 